\title{
Buddha Contemplation: Development of a Training Model to Improve Community Leader Virtue in the Central Region of Thailand
}

\author{
Wanpen Khemakanok ${ }^{1}$, Kla Somtrakul $^{1} \&$ Wisanee Siltrakul ${ }^{1}$ \\ ${ }^{1}$ The Faculty of Cultural Science, Mahasarakham University, Khamriang Sub-District, Kantarawichai District, \\ Maha Sarakham, Thailand \\ Correspondence: Wanpen Khemakanok, The Faculty of Cultural Science, Mahasarakham University, Khamriang \\ Sub-District, Kantarawichai District, Maha Sarakham 44150, Thailand. E-mail: one.pen@live.com
}

\author{
Received: September 7, 2013 Accepted: September 17, 2013 Online Published: November 29, 2013 \\ doi:10.5539/ass.v9n17p279 URL: http://dx.doi.org/10.5539/ass.v9n17p279
}

\begin{abstract}
This qualitative research aimed: a) to study the training model for developing the virtue of community leaders in central Thailand; b) to study the problems and suggestions of the training model for developing the virtue of community leaders in central Thailand; c) to develop the training model for developing virtue of community leaders in central Thailand. The research area consisted of three provinces in Central Thailand, Nakhon Nayok, Pathumthani and Phra Nakhon Si Ayutthaya. The research tools were preliminary survey, interview, observation, group discussion and workshop. Field data was collected from three groups of informants. The collected data was validated using a triangulation method and analyzed in accordance with the research objectives. The research results were presented as a descriptive analysis. The final results led to the setup of a new model of training, which can be called the 'Buddha Contemplation: Development of a Training Model to Improve Community Leader Virtue'. The content of the course takes four Buddhist principles as its foundation: Sammaditthi (right views), Jarit (behavior), Sikkha (training) and Bhavana (development). The training method is on the principle of the kanlayanmit (seven suitable preparation conditions). The development of the training model for developing community leader virtue based on the Buddha Contemplation method can be implemented as a training technique for more effective development of community leader virtue.
\end{abstract}

Keywords: Buddha contemplation, development, training model, improvement, virtue, community leaders

\section{Introduction}

In past Thai society, people lived in groups with one group leader at their head. The leader was responsible for administration and government of the everyday life in society to ensure that the people lived safely, comfortably and happily. They were role models for the community. Community heads have been respected by the people from the past until the present day, as Thai society recognizes the importance of its leaders. The main attribute of a good community leader is virtue. Training of virtue among community leaders in the past was influenced by monk ordination in the Buddhist religion. However, there is currently a leadership crisis and the training of virtue among community leaders must be developed so that it is appropriate.

\section{Research Aims}

This qualitative research aimed: a) to study the training model for developing the virtue of community leaders in central Thailand; b) to study the problems and suggestions of the training model for developing the virtue of community leaders in central Thailand; c) to develop the training model for developing virtue of community leaders in central Thailand.

\section{Research Methodology}

This was a qualitative investigation that employed document research and field study in order to study the training model for developing the virtue of community leaders in central Thailand, identify problems with the training model, make corrective suggestions and develop the training model. The results of this research were presented to a panel of experts to identify an ideal training model for future implementation. The research area consisted of three provinces in Central Thailand, Nakhon Nayok, Pathumthani and Phra Nakhon Si Ayutthaya. The institutions covered in the research area were the Virtue Training Centre at Wat Panyanantaram in Pathumthani Province, Institute for the Development of Thai Community Leader Ability in Nakhon Nayok 
Province, Mahamakut Buddhist University, Mahavajiralongkorn Rajavidyalaya Campus in Phra Nakhon Si Ayutthaya Province and Mahachulalongkornrajavidyalaya University, Wang Noi Campus in Phra Nakhon Si Ayutthaya Province. Three informant groups were used in data collection, totaling fifty-seven individuals. Data was collected by survey, structured and non-structured interview, participant and non-participant observation, group discussion and workshop. The collected data was validated using a triangulation method and analyzed in accordance with the research objectives. The research results were presented as a descriptive analysis.

\section{Results}

The target group for training to develop community leaders in central Thailand is local leaders, local leadership groups and general people. The institutions that organize the training courses define the target groups according to the aims and content of the programs. The programs are set to promote virtues, life skills, implementation of Bhavana and leadership. The training courses take the form of lectures and include the use of media and practical tasks defined by the lecturers or experts from the organizing institute or those who have been hired from outside. The expected outcomes of the training courses are promotion of personal skill, attentiveness, concentration and leadership. The duration of the courses depends on the curriculum used by the organizing institute and the locations used within the institute and externally. Evaluation and assessment is conducted at the end of the training course in the form of a questionnaire.

Research found that the target groups do not match the objectives of the training courses, so the target group must be more clearly defined. In some areas, the aims of the training courses are inadequate and insufficient. Values should therefore be established as the concrete principle behind the courses. The course content emphasizes external development of the individual, so there should be allowance for personal consideration and influence in individual development. The students of the course are not considered important. There must be increased participation to remedy this failing. The benefits received from the courses are not clear, so there must be continual development of the trainers to cure this. The lecturers still use the same methods and data as the past and they are the center of learning. Focus should be switched to a student-centered approach. The course duration is inappropriate and should be fixed at three days and two nights. The course locations should have suitable conditions and the evaluation and assessment should concern all activities rather than a general overview.

The model for developing virtue of community leaders in central Thailand takes a target group of local community leaders in central Thailand. The aims are to promote values, honesty, patience, diligence and sensibility. The content of the course takes four Buddhist principles as its foundation: Sammaditthi (right views), Jarit (behavior), Sikkha (training) and Bhavana (development). The training method is on the principle of the kanlayanmit (seven qualities of a true friend), internal learning and continual adaptation. The benefits that trainees should receive are values, honesty, patience, diligence and sensibility. The trainers should have qualities according to the kanlayanmit, which are loveable, respectable, joyful, knowing when to speak, patient, profound and not guiding down the wrong path. The duration of the model course is three days and two nights. The location is the Suntriya Sontana Donfa Training Center or another convenient location with the appropriate number and quality of facilities. 


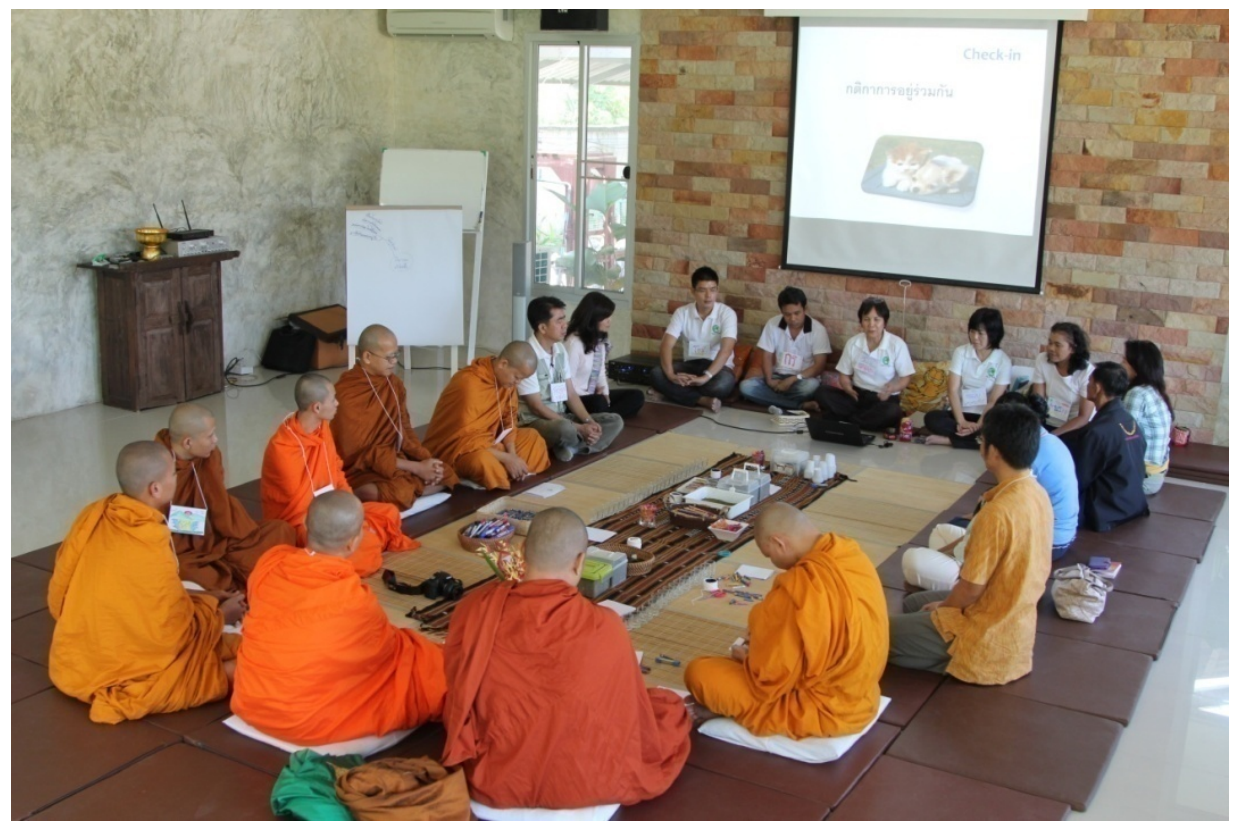

Figure 1. The atmosphere of a seminar meeting during a Buddha contemplation training course, using the methods of the kanlayanmit by sitting in a circle, according to the concepts of contemplative education

\section{Discussion}

There are many organizations that offer training courses to promote virtues in local community leaders and the researchers selected four such institutions in the central region of Thailand to help identify an ideal model for their implementation. These four locations were the Virtue Training Centre at Wat Panyanantaram in Pathumthani Province, Institute for the Development of Thai Community Leader Ability in Nakhon Nayok Province, Mahamakut Buddhist University, Mahavajiralongkorn Rajavidyalaya Campus in Phra Nakhon Si Ayutthaya Province and Mahachulalongkornrajavidyalaya University, Wang Noi Campus in Phra Nakhon Si Ayutthaya Province. It was found that there are nine structures to the courses at the four institutions, which are all inter-related. This means that if one aspect lacks suitability or is incomplete, the others will be affected. Additionally, it was found that religious beliefs, customs and culture had an effect on the development of virtues. The institutions taking responsibility for the training courses have an important role in the development of virtues but there remains limited cooperation. The integration of expertise is also limited and this means that the success of the course is limited as each department concentrates solely on their own responsibilities. This idea links with the research of Radcliffe-Brown (1952) and the development of a structural-functional theory, which stated that different levels of society and their structures were intrinsically linked.

Aside from this, it was found that the majority of institutions holding training courses were related in some way to the Buddhist religion. These institutions were extremely important as they developed the characteristics of local leaders and provided them with an opportunity to train in religious beliefs, customs and lifestyle. The researchers thus realized the importance of these institutions and their intimate relationship with the development of local leadership. This links to the work of George Herbert Mead (1964), which suggested that culture causes enlightenment, which in turn causes the development of personal characteristics. This is also in agreement with the research of Gardiner (1978), which found that cultural planning had an influence on personality, with religion, local stories, political systems and the raising of children linked to the social economy as the foundation for building character.

The model for training along the model of Buddha contemplation is based on the foundation that all people have the ability to develop themselves. This is linked to the view of Greenberg (2002), and the ideas of the Moral Promotion Center (2008), which placed importance on the good conditions of all areas of the external surrounding environment. These must be appropriate for the development of internal leadership values, which are known as yonisomanasikära and enable the trainees to self-learn and self-develop leadership skills. The leaders are able to teach themselves, or if not, there are many government and religious institutions in the central region of Thailand where they may receive training, especially the Institute for the Development of Thai Community Leader Ability in Nakhon Nayok Province. This institution specializes in the development of 
leadership skills among local community heads. Given the large number of institutions specializing in leadership development, the researchers found that, for successful development, there must be a suitable and varied training curriculum and model, as well as integration with the institution. Then the leaders may learn to teach themselves. This is in alignment with the research of Park (2009), which considered knowledge through practice of the art of being a good leader.

The content of the course emphasizes values according to the community economy, which are honesty, patience, diligence and sensibility. Also stressed are the importance of the four Buddhist principles of developing the physique, mind, sociability and contemplation. These agree with the three ways of contemplation in the new development of people, as explained by Worapat Pujaroen (2011), who said that people have three ways of contemplation: the body, the heart and the mind.

There were found to be two components of the training process, kanlayanmit for external development and yonisomanasikarra for internal development. These findings agree with the learning process for adaptation of contemplative education, for which there are two important characteristics. The first is creation of conditions that allow the existing ability to be developed and the second is process of participation, whereby the trainers must also learn along with the trainees (Ninchaikowit, 2009). From this research the design of training courses there were a number of steps, which included preparation, threefold training (sikkha) and evaluation and assessment. These steps correspond to those outlined by Christopher Johnson (2008), who identified four steps: preparation, presentation, practice and performance.

The model created in this study emphasized a student centered approach. For this reason, there must be trainee participation in the planning, consultation and evaluation of training. The trainers must also possess the seven personal characteristics of kanlayanmit. These characteristics are in alignment with the five identified by contemplative education, which are: a) real knowledge; b) lateral thinking; c) listening and acceptance of differences; d) ability to render assistance and ability to provide warmth; e) stability, sensibility, peace, love, compassion and deep and detailed understanding (Ninchaikowit, 2009).

The evaluation of model training courses using Buddha contemplation to promote virtues in community leaders emphasized the assessment of real conditions. The trainees must evaluate the variety and detail of the courses themselves. This evaluation method is in correspondence with the method outlined by Greenberg (2002), which who noted that the only people able to evaluate the benefit of the training courses for the trainee was the trainee themselves. For this reason, self-evaluation is an important part of the training process.

\section{References}

Gardiner, R. A. (1978). Design for Safe Neighborhood. Washington, D.C.: Printing Office.

Greenberg, H. M. (2002). Love learning, learn through love. Bangkok: Kanghan.

Johnson, C. (2008). Creation of a learning environment for Thai people. Bangkok: Jaroenkanpim.

Mead, G. H. (1964). Selected Writings: George Herbert Mead. In A. J. Reck (Ed.). Chicago: University of Chicago Press.

Moral Promotion Center. (2008). Research program for developing the curriculum for training and process of contemplative learning. Bangkok: Moral Promotion Center.

Ninchaikowit, T. (2009). The art of managing learning processes for adaptation: manual for the process of contemplation. Bangkok: Center of Contemplative Education, Mahidol University.

Park, C. D. (2009). Leadership classes of Harvard. Bangkok: McGraw Hills.

Pujaroen, W. (2011). The development of people, the development of heart, giving heart to organizations. Bangkok: Ariyachon Jamgat.

Radcliffe-Brown, A. R. (1952). Structure and Function in Primitive Society. Oxford: Oxford University Press.

\section{Copyrights}

Copyright for this article is retained by the author(s), with first publication rights granted to the journal.

This is an open-access article distributed under the terms and conditions of the Creative Commons Attribution license (http://creativecommons.org/licenses/by/3.0/). 